\title{
Thermal properties of processed lunar regolith simulant
}

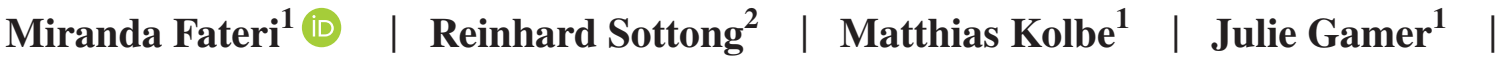 \\ Matthias Sperl $^{1}$ | Aidan Cowley ${ }^{3}$
}

\author{
${ }^{1}$ Institut für Materialphysik im \\ Weltraum, Deutsches Zentrum für Luft- und \\ Raumfahrt (DLR), Köln, Germany \\ ${ }^{2}$ Institut für Werkstoff- \\ Forschung, Deutsches Zentrum für Luft- \\ und Raumfahrt (DLR), Köln, Germany \\ ${ }^{3}$ European Astronaut Centre (EAC), Köln, \\ Germany

\section{Correspondence} \\ Miranda Fateri, Institut für Materialphysik \\ im Weltraum, Deutsches Zentrum für Luft- \\ und Raumfahrt (DLR), Köln, Germany. \\ Email: miranda.fateri@gmail.com \\ Funding information \\ European Space Agency
}

\begin{abstract}
In this paper, the thermal characterization of lunar regolith simulant, sintered using a conventional oven under ambient and vacuum conditions is presented. Additionally, thermal characterization of samples is performed for the parts manufactured using solar, laser, and microwave processing. Samples for oven sintering are prepared using regolith bulk simulant as well as simulant pressed at $255 \mathrm{MPa}$ for $10 \mathrm{~min}$ utes. Similar experiments are performed with a mixture of Johnson Space Center (JSC)-2A $+20 \mathrm{wt} \%$ of ilmenite, a common lunar mineral. Samples are characterized regarding their thermal capacity, thermal diffusivity, density, and thermal conductivity. Furthermore, sample morphology is studied using scanning electron microscopy. Lastly, processing of regolith for lunar thermal energy storage is discussed.
\end{abstract}

\section{K E Y W O R D S}

ISRU, moon, regolith, sintering, thermal energy storage

\section{1 | INTRODUCTION}

Future exploration of the Moon is in the exploration roadmaps of major space agencies ${ }^{1}$, as is the need to make such exploration a sustainable endeavor. In this context, In-Situ Resource Utilisation (ISRU) is attracting a considerable degree of attention as a means to realize such sustainable exploration ambition. Regarding lunar ISRU, the focus has predominantly been on utilizing the loose (bulk) regolith material abundantly found on the lunar surface, as a source of volatiles or potentially utilized in construction. ${ }^{2-4}$

In the context of terrestrial testing with regolith or investigating ISRU applications, the available actual lunar soil for laboratory experiments is scarce as less than $400 \mathrm{~kg}$ was returned from the Apollo missions. ${ }^{5}$ This hinders the use of actual lunar regolith for in situ construction investigation, which would necessitate altering the regolith samples. Hence, simulant materials are used for such investigations. Materials on the Moon are divided in two categories of anorthositic (highlands) and basaltic (maria) rocks. As reported, lunar regolith contains several minerals such as pyroxene (augite, diopside, enstatite, hedenbergite), plagioclase (anorthite, albite), olivine (fayalite, forsterite), and oxides (ilmenite, magnetite, hematite) which are also known in terrestrial rocks. ${ }^{6}$

Based on the reported data ${ }^{6}$ of actual lunar samples, simulants created from mined volcanic ashes have been developed in order to enable the use of terrestrial materials for lunar application.

Regarding the lunar simulant development, Johnson Space Center (JSC) from National Aeronautics and Space Administration (NASA) mimicked Apollo samples of 14 163, (using Arizona mined volcanic sediments) by categorizing a lunar regolith simulant called JSC-1, which represented the mare regolith with low titanium content. ${ }^{7}$

Over time and as needs demanded, different space agencies introduced various simulants such as DNA (mare simulant), FJS (mare simulant in three different types with low and high titanium content), and NU-LHT (highlands). ${ }^{8}$

Nonetheless, JSC-1 is among the widely used and published test materials so far and its chemical and physical properties such as minerals and particles size distribution are well evaluated and compared to the actual lunar Apollo samples. ${ }^{7}$ 
Additionally, previously obtained results during the ESAGSTP (General Support Technology Programme, Study No. $4000112759 / 15 / \mathrm{NL} / \mathrm{PA}$ ), concluded that JSC-1 is a proper candidate for the lunar exploration studies. However, JSC-1A (supplied by Orbital Technologies Corporation) is not commercially available anymore and has been recently replaced by a similar version called JSC-2A (supplied by Zybek Advanced Products).

Following these, in this investigation, JSC-1A and JSC-2A simulants were studied regarding their suitability for a sintering process, targeting lunar manufacturing. Furthermore, a variation in regolith compositions, including higher contents of ilmenite $\left(\mathrm{Fe}^{2+} \mathrm{TiO}_{3}\right)$ as a primary source of titanium on the Moon ${ }^{7}$ was considered as the alternative test material in this study. To form the regolith, different approaches such as layer-wise shaping of granulate using additives, binders and ink ${ }^{9,10}$, compression ${ }^{11}$ and direct heating ${ }^{12}$ are reported. Direct heating of regolith, eliminates the need of any additional material transport or lunar on-site resource extraction; thus, leading to a more efficient process when comparing to the other introduced techniques. ${ }^{9,10}$

Among the published data regarding the direct heating of regolith, sintering/melting of regolith using microwaves ${ }^{13}$, concentrated solar energy ${ }^{14}$, and laser (selective laser sintering and melting [SLS/SLM] $)^{15,16}$ are among the most viable and published techniques for ISRU application. All these techniques have their own advantages and drawbacks.

Absence of atmosphere on the Moon makes the vacuum sintered samples proper candidates as reference samples for lunar on-site manufacturing as the oxidization of the material is avoided. However, abrasive properties of regolith, makes it an undesirable material for investigations under vacuum. Using SLS and SLM, oxidization of the sintered samples is also avoided using argon (as a typical inert gas for SLS and SLM). However, the complete absence of any atmosphere is not simulated using this process.

From the energy source availability aspect, solar sintering and/or melting is the most feasible on-site manufacturing method due to the constant light source on the Moon (depending on the selenological coordinates and cycle) and absence of atmospheric weathering and humidity.

In this work, we applied many widely considered approaches to ISRU processing of lunar regolith, fabricating parts using different sintering and melting techniques and then characterized them regarding their thermal characteristics. So far, reported data regarding the thermal properties of lunar regolith simulants are limited to the regolith in its powder form. ${ }^{17}$

In this study, conventional ovens capable of processing the regolith under air and vacuum were applied in order to produce sintered products from pressed and non-pressed samples. Furthermore, regolith was sintered using solar, laser, and microwave energy. In this investigation, all applied process parameters for sample preparations were selected from the published data. Corresponding references will be found in methodology section.

Lastly, fabricated parts were studied regarding their heat conductivity by measuring their heat capacity, heat diffusivity, and density.

\section{2 | MATERIAL}

In this study, particle size distribution measurements for JSC-1A and JSC-2A were conducted using a Malvern particle analyser. Measurements were conducted three times for each simulant, indicated in different colors in Figure 1.

As results show, there is a slight variation in particle size distribution between JSC-1A and JSC-2A simulants. Measurements resulted in D (10) of 33 and $19 \mu \mathrm{m}, \mathrm{D}(50)$ of 210 and $145 \mu \mathrm{m}$ and $\mathrm{D}(90)$ of 1210 and $551 \mu \mathrm{m}$ for JSC-1A and JSC-2A, respectively. Measurements showed that JSC-1A has a D [4;3] of $443 \mu \mathrm{m}$ and JSC-2A has a D [4;3] of $253 \mu \mathrm{m}$. The slight differences in shape and distribution between JSC-1 A and JSC-2A particles were also observed by the scanning electron microscopy (SEM)-(Zeiss LEO 1530 VP) results as shown in Figure 1. Nevertheless, JSC-2A fits to approximately $95 \%$ to the upper and lower bounds (2) of the particle size of investigated Apollo samples.

In the next step, the general melting behavior of the JSC-2A was studied using differential scanning calorimetry (DSC)-(Pegasus $404 \mathrm{C}$ ). The DSC results of JSC-2A powder are shown in Figure 2 which exhibited three main transformation phases. The results showed that the glass transition occurred at $620^{\circ} \mathrm{C}$. At $800^{\circ} \mathrm{C}$ and $1070^{\circ} \mathrm{C}$ the crystallization and melting peaks appeared, respectively.

The DSC results of JSC-2A were similar to the reported data ${ }^{18}$ regarding melting of JSC-1A simulant.

Results regarding the particles size distribution, SEM and DSC measurements showed physical and chemical similarities of JSC-1A and JSC-2A.

Following these, JSC-2A was concluded to be viable test material for this investigation.

\section{3 | METHODOLOGY}

In the following, various samples were produced using different methods (laser ${ }^{15,16}$, conventional ${ }^{18}$ solar $^{19}$ and microwave $^{20}$ sintering) by applying optimal process parameters obtained during previous investigations.

In the first step, samples were produced by conventional sintering with a diameter of $20 \mathrm{~mm}$ and a height between 10 and $20 \mathrm{~mm}$. Bulk and pressed JSC-2A powder was sintered as the green body under air and vacuum (7E-6 mbar) conditions. Pressing was carried out using an Atlas-Specac Hydraulic 
JSC-1A

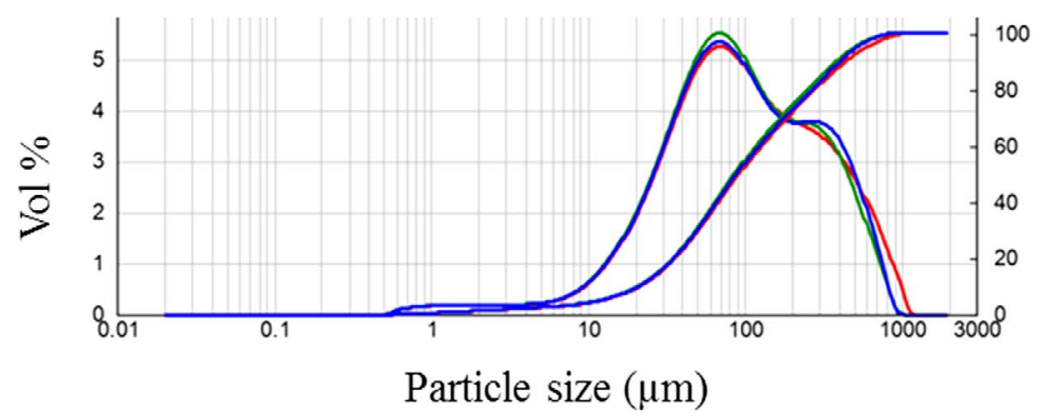

JSC-2A

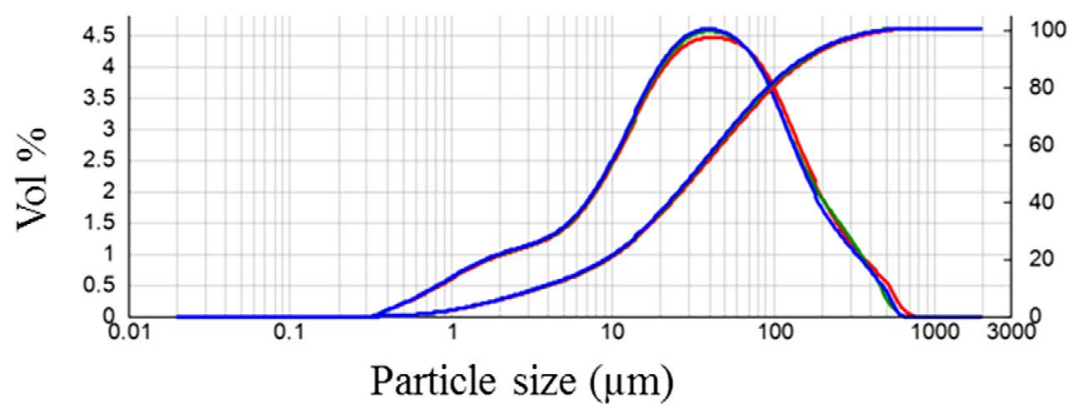

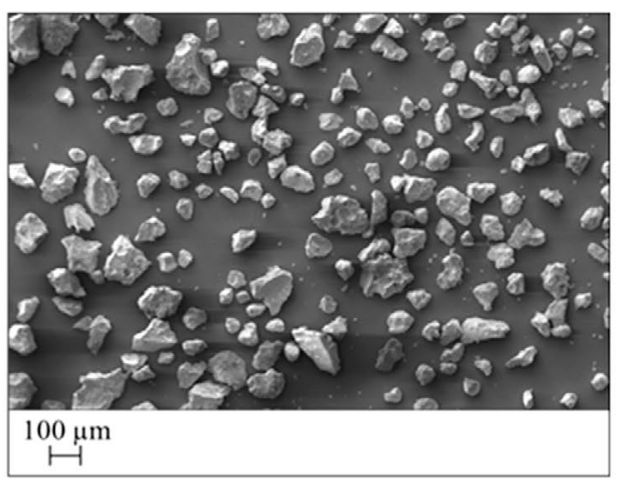

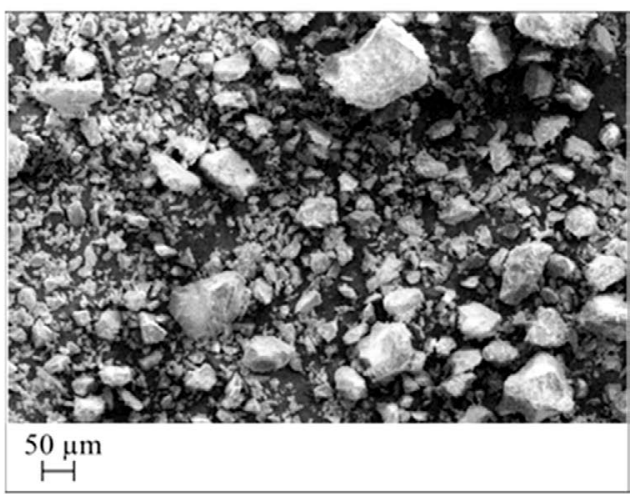

F I G U R E 1 Particle size distribution and SEM of JSC-1A (top) vs JSC-2A (bottom). JSC, Johnson Space Center; SEM, scanning electron microscopy

(15 T) machine by applying a 255 MPa pressure for a holding time of 10 minutes. For the experiments, Linn High-Therm oven and GERO thermal oven were used for ambient and vacuum sintering respectively. ${ }^{18}$

A custom made solar 3D printer was applied to sinter and melt the JSC-2A material (under ambient condition). Two Xenon lamps ([6 kW per lamp] in which the Xenon light represented a spectrum close to the sunlight) were used as a proxy for the lunar lighting conditions-real terrestrial sunlight found to be sub-optimum for 3D printing application, due to the variation in light intensity during the process (clouds, humidity, etc). Light from the Xenon lamps was concentrated in a parabolic mirror and further projected on a flat mirror resulting in a $12 \mathrm{~mm}$ focus diameter spot and a flux density of $1200 \mathrm{~kW} / \mathrm{m}^{2}$ (at the focal point). Regolith deposition was done using a powder feeder which delivered the regolith by a vibration mechanism attached to a powder container and tray while layering was done using a XYZ table (with an adjustable speed; namely called as scanning speed). ${ }^{19}$

SLM processed regolith samples were fabricated using an SLM-solution laser machine equipped with a maximum laser power of $100 \mathrm{~W}$ (laser type: IPG fibre laser, wavelength: $1070 \mathrm{~nm}$ ) and a laser focus diameter of $100 \mu \mathrm{m}$. parts were fabricated under argon gas environment. Regolith deposition

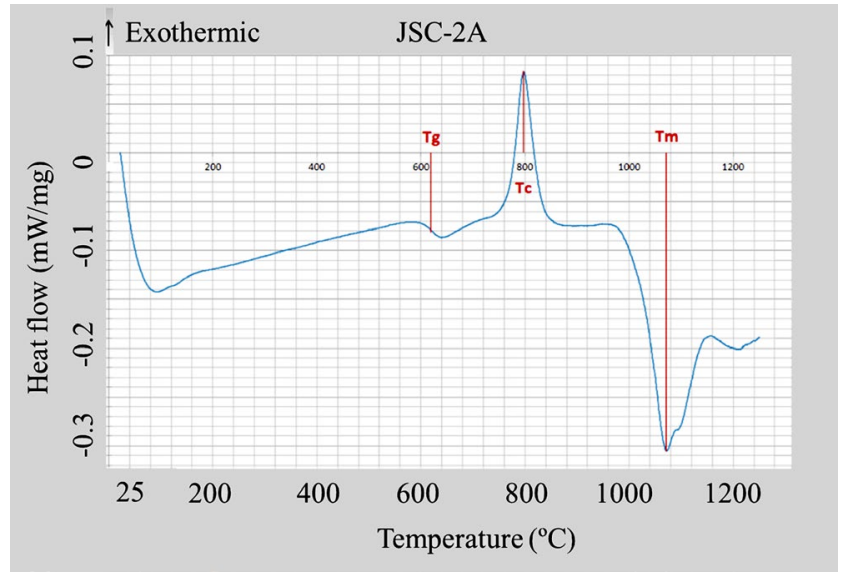

F I G U RE 2 DSC measurement results for JSC-2A simulant. DSC, differential scanning calorimetry; JSC, Johnson Space Center

was done using a wiping mechanism while layering was conducted by lowering the build platform. ${ }^{15}$

A modified microwave oven (Inverter NN-SD452W microwave equipped with a maximum power of $950 \mathrm{~W}$ ) for regolith applications was applied to sinter/melt the regolith simulant. Powder was poured in a ceramic (alumina) 
crucible, placed at the microwave's hot spot and processed using ambient conditions. ${ }^{20}$

Prepared samples using above fabrication technologies were subsequently characterized using laser flash analysis (LFA) by a Netzsch Gerätebau device LFA 427 between room temperature and $150^{\circ} \mathrm{C}$ under vacuum for thermal diffusivity measurements.

Using DSC, specific heat capacity of the samples was measured in the temperature range between $-100^{\circ} \mathrm{C}$ and $150^{\circ} \mathrm{C}$ under inert atmosphere. Furthermore, envelope densities of the samples were measured using a density analyser Micromeritic GeoPyc. True (skeletal) density of the JSC-2A regolith simulant was measured using a gas pycnometer Micromeritic AccuPyc II 1340. Moreover, morphology of fabricated samples was examined using SEM.
Consequently, thermal conductivity as a function of temperature was derived ${ }^{21}$ based on the obtained data of thermal diffusivity, heat capacity, and fabricated part's envelope density as follows.

$$
k(T)=\alpha(T) \times c_{p}(T) \times \rho(T)
$$

where $k(\mathrm{~W} / \mathrm{m} \times \mathrm{K})$ is the thermal conductivity, $\alpha\left(\mathrm{mm}^{2} / \mathrm{s}\right)$ is thermal diffusivity, $\rho\left(\mathrm{g} / \mathrm{cm}^{3}\right)$ is the density, $c_{p}(\mathrm{~J} / \mathrm{g} \times \mathrm{K})$ is the heat capacity.

Samples fabricated using different technologies are shown in Figure 3. Fabricated samples differed in shape and colour depending on their fabrication techniques and atmospheres. Samples with relatively poor mechanical properties crumbled into pieces due to their separation from their crucible and/

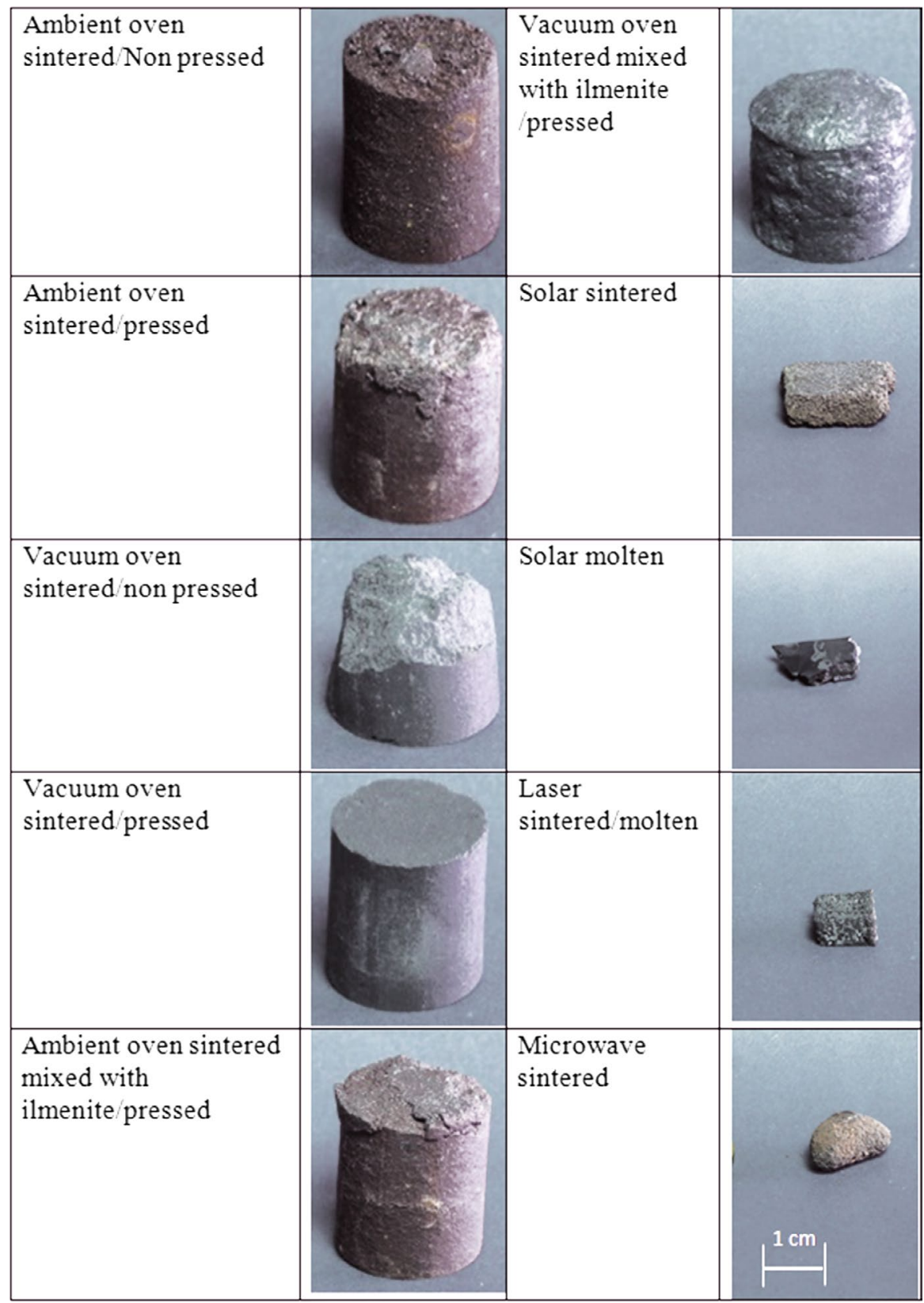

FIGURE 3 Fabricated parts using different strategies mentioned in methodology section, the scale bar applies for all the fabricated samples 
or build platforms. For the measurements, prepared samples were cut using a diamond wire to the size of $10 \times 10 \times 1 \mathrm{~mm}^{3}$.

\section{\begin{tabular}{l|l}
4 & RESULTS AND DISCUSSION
\end{tabular}}

Obtained samples were analyzed regarding their envelope density, thermal diffusivity and heat capacity and their corresponding thermal conductivity was calculated and discussed in this section. It should be noted that errors bars were negligible; thus, not included in the results.

\section{1 | Density}

Density measurement results of the samples are presented in Table 1. As expected, sintering the pressed samples resulted in higher densities compared to the non-pressed ones, regardless of the sintering technique and conditions. As the results showed, solar sintered and JSC-2A +20 (wt\%) ilmenite sintered using conventional oven (pressed before sintering) samples have the lowest and highest density, respectively (among the measured samples). Solar sintered samples resulted in a density of approximately $54 \%$ of regolith's true density.

Low density of the solar sintered samples could be explained by their fabrication approach in which layering of the regolith was conducted with the help of a vibration mechanism. In this system, regolith was poured into a container and spread over the build platform by vibrating an inclined plate attached to the container. ${ }^{19}$ Therefore, not only the powder bed was not compacted, but no clear surface contact among the particles was granted. Furthermore, due to the rapid heating and cooling rate during the solar AM process, particles did not undergo a proper sintering time. Consequently, the punctual contact among the particles and

TA B L E 1 Density measurements results of different processed samples

\begin{tabular}{|ll|}
\hline Sample & Density $\left(\mathbf{g} / \mathbf{c m}^{\mathbf{3}}\right)$ \\
\hline $\begin{array}{l}\text { Ambient oven sintered mixed with ilmenite/ } \\
\text { pressed }\end{array}$ & 2.57 \\
\hline Vacuum oven sintered/pressed & 2.51 \\
\hline $\begin{array}{l}\text { Vacuum oven sintered mixed with ilmenite/ } \\
\text { pressed }\end{array}$ & 2.31 \\
\hline Vacuum oven sintered/non pressed & 2.42 \\
\hline Ambient oven sintered/pressed & 2.41 \\
\hline Solar molten & 2.33 \\
\hline Laser sintered & 2.32 \\
\hline Ambient oven sintered/non pressed & 2.30 \\
\hline Microwave sintered mixed with ilmenite & 2.24 \\
\hline Solar sintered & 1.57 \\
\hline
\end{tabular}

the relatively short sintering time led to a final structure with a high porosity. Density of solar processed parts was improved to $80 \%$ of the regolith's true density by melting the matter in relatively slow scanning process (during the AM-layer scanning: $30 \mathrm{~mm} / \mathrm{s}$ ). Laser sintered and solar molten samples exhibited similar densities. Relatively small laser focus diameter $(100 \mu \mathrm{m})$ and relative high absorptivity of regolith in NIR ${ }^{15}$ led to high energy intensity during the process; thus, liquid phase sintering occurred during the SLS/SLM process.

Regarding the oven sintered parts, loose sintered regolith under vacuum showed a similar density to the pressed sintered regolith under ambient condition.

Adding ilmenite to the JSC-2A, improved sample's density sintered using the air compared to the ones sintered under vacuum.

It should be noted that ilmenite has a higher true density $\left(4.72 \mathrm{~g} / \mathrm{cm}^{3}\right)$, comparing to JSC-2A $\left(2.90 \mathrm{~g} / \mathrm{cm}^{3}\right)$.

\section{2 | Scanning electron microscopy}

Density measurement results were followed by SEM analysis (see Figure 4) of the fabricated samples. SEM of oven sintered samples show that, when sintered under ambient conditions, an up to $1 \mu \mathrm{m}$ thick layer of oxide was formed at the grain boundaries (eg, $\mathrm{MgO}$ and $\mathrm{Fe}_{2} \mathrm{O}_{3}$ around an olivine phase) ${ }^{18}$ while under vacuum oxidization of the material was prevented. Additionally, material undergoes the outgassing while implementing vacuum sintering. This explains why vacuum sintered parts have higher density compared to the ambient sintered parts. SEM of sintered mixture powder (ilmenite and regolith) showed porosities up to $50 \mu \mathrm{m}$ under air, and porosities up to $300 \mu \mathrm{m}$ under vacuum. Magnified images of sintered mixture (see Figure 5) relieved an ironrich boundary between the molten ilmenite and other existing minerals in one cut plane. Iron-rich boundary appeared in minerals with sharp and round edges under vacuum and air respectively. Detailed investigation behind these observations is not in the scope of this study.

For SEM, solar sintered part was not polished due to its fragile structure. SEM of solar sintered part showed the nonhomogeneous and weak regolith particle's interconnections which confirmed the density measurement results. In order to have comparative results, SEM of solar molten parts was conducted at a non-polished surface. As it can be seen in Figure 4 , solar molten part consist of molten lines of approximately $500 \mu \mathrm{m}$, embedding un-melted minerals such as plagioclase. Outgassing can be seen by small bubble formation beside the molten lines. Balling effect of the solidified material can be also seen in texture of solar molten material (see Figure 4: marked as f).

SLM sample showed no traces of the minerals but exhibited round porosities ranging from 10 to $200 \mu \mathrm{m}$. 


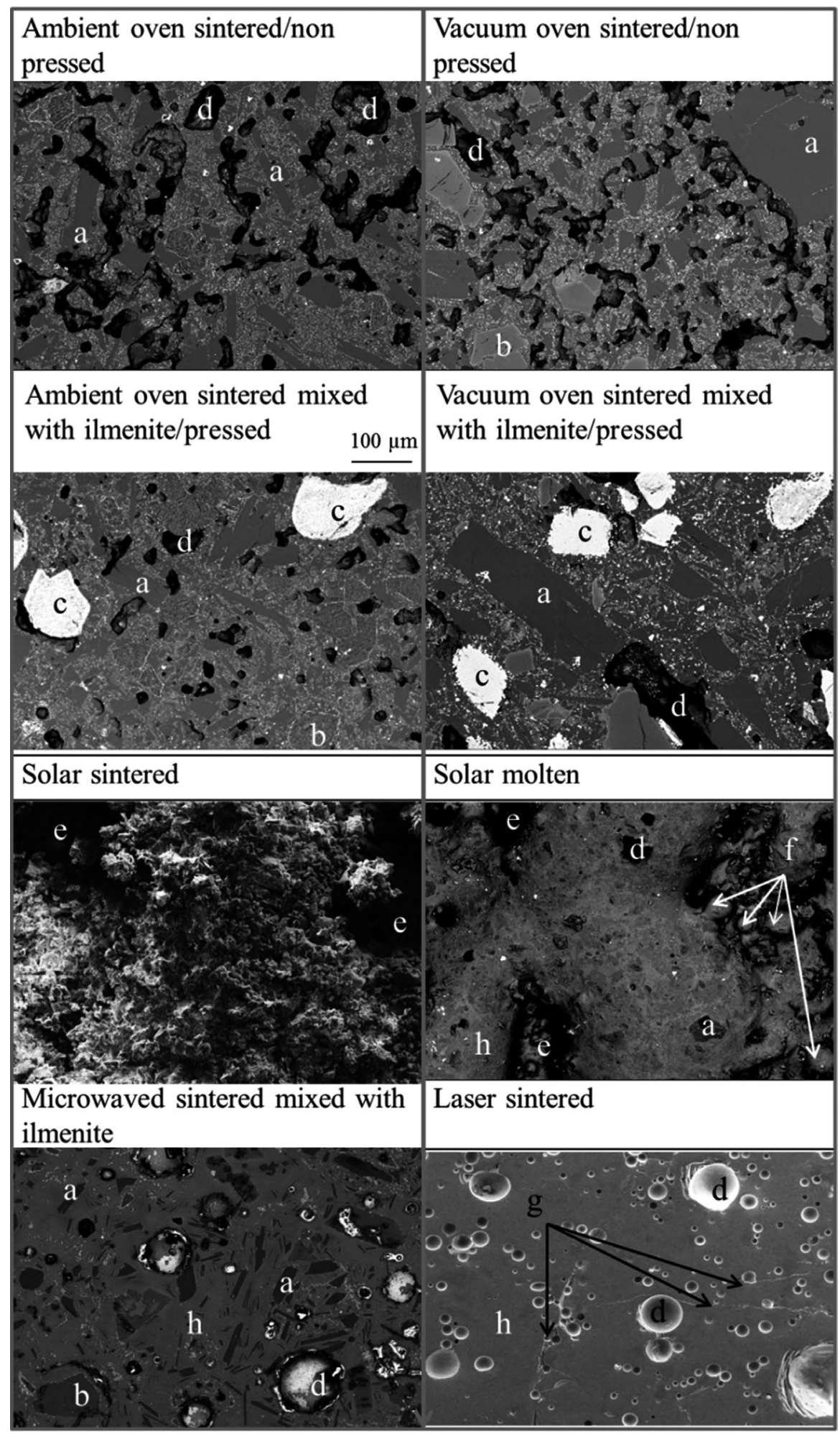

F IG URE 4 SEM images of different parts fabricated using different manufacturing techniques (a: plagioclase, b: olivine, c: ilmenite, d: porosity, e: broken bridges within the molten lines: f: balling effect, h: glass); scale bar applies for all the images. SEM, scanning electron microscopy
Crack formation originating from the bubbles was also observed in morphology of the laser molten parts. These crack formations could be due to the relatively rapid heating and cooling of the scanned area. In addition to the bubbles, re-melting of the solidified tracks (during the layer scanning) could also be the reason behind the crack formation (see Figure 4, marked as g).

\subsection{Thermal diffusivity}

Thermal diffusivity of the samples was measured using LFA. Thermal diffusivity and the heat capacity values of the studied samples are shown in Figure 6 (legends are applied for Figures 6-8).

LFA measurement of parts with the higher densities (oven sintered parts) resulted in lower thermal diffusivity values 


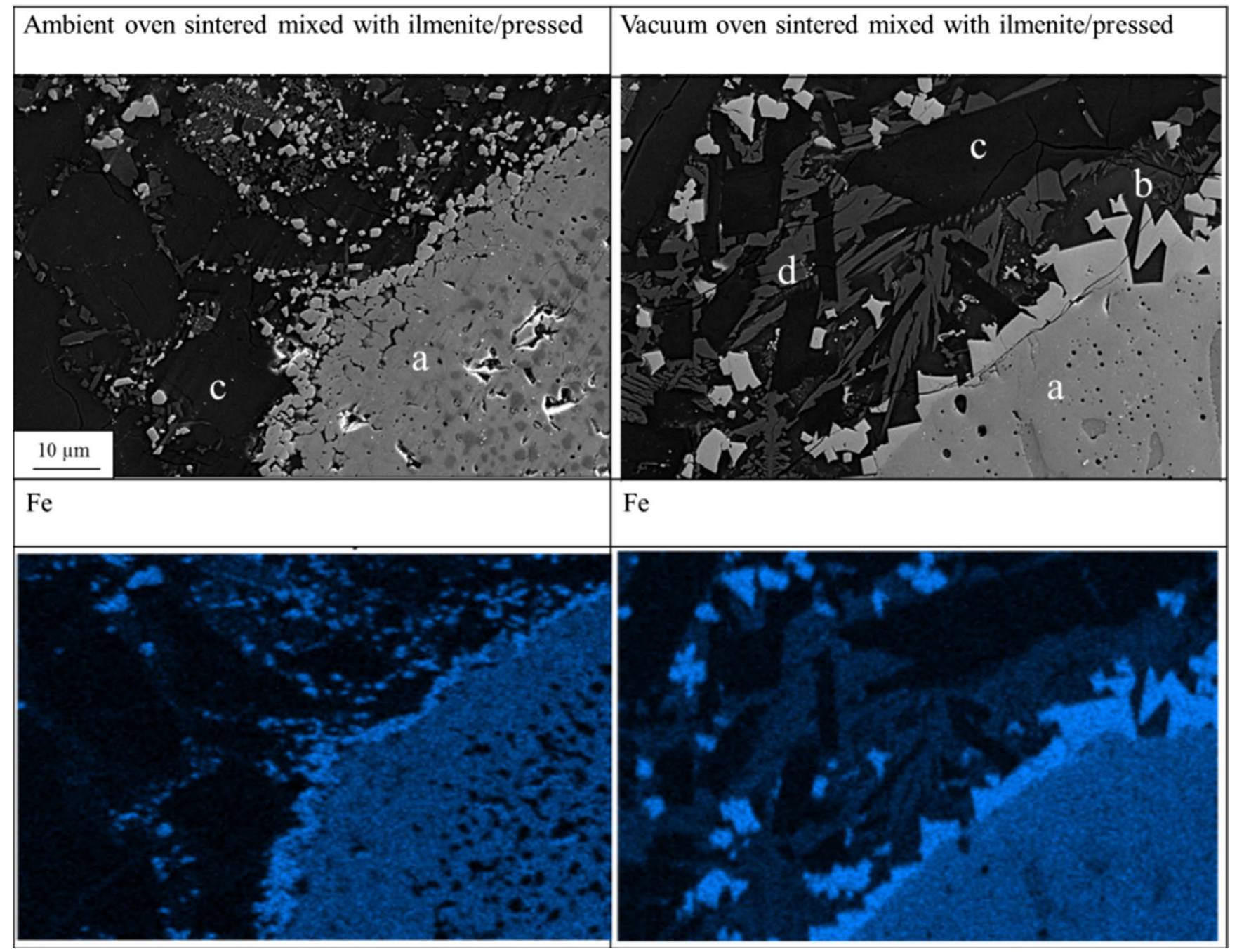

F I G U R E 5 SEM images of sintered parts (regolith and ilmenite mixture); using air (top-left), under vacuum (top-right) (a: ilmenite, b: feldspar, c: plagioclase, d: diopside), iron- rich areas of the corresponding SEM images (bottom); scale bar applies for all the images. SEM, scanning electron microscopy

compared to the other sintered parts (fabricated using alternative manufacturing techniques).

For the parts manufactured under ambient condition, in addition to the impact of the part's density on thermal diffusivity (due to the grains orientations and connections), the oxide layers formed around the grains under ambient condition might influence the measured thermal diffusivity values. Among the measured samples, laser sintered part, represents the highest thermal diffusivity value. In general, results regarding the thermal diffusivity measurements showed a contradictory trend compared to the density measurement results. Following this trend, ambient oven sintered regolith mixed with ilmenite/pressed exhibited the lowest thermal diffusivity among the studied samples.

\subsection{Heat capacity}

Heat capacity results of measured samples (using DSC) are shown in Figure 7. As the results showed, specific heat capacity of all processed samples increase linearly within the measured temperature range.

Results of all studied samples led to the same value of $0.74(\mathrm{~J} / \mathrm{g} \times \mathrm{K})$ at the room temperature. It can be concluded that, the specific heat capacity of manufactured samples using different techniques (considering a constant temperature) does not vary significantly (maximum variation: $\sim 0.04 \mathrm{~J} / \mathrm{g} \times \mathrm{K})$.

\section{5 | Thermal conductivity}

Results of the thermal conductivity measurements of different samples are shown in Figure 8. Solar sintered part exhibited the lowest thermal conductivity values among the studied samples $\left(0.55 \mathrm{~J} / \mathrm{g} \times \mathrm{K}\right.$ at the $25^{\circ} \mathrm{C}$ and $0.60 \mathrm{~J} / \mathrm{g} \times \mathrm{K}$ at the $\left.150^{\circ} \mathrm{C}\right)$.

This sample had the lowest density compared to the other samples. Moreover, laser molten samples showed the highest thermal conductivity $\left(1.10 \mathrm{~J} / \mathrm{g} \times \mathrm{K}\right.$ at the $25^{\circ} \mathrm{C}$ and $1.20 \mathrm{~J} / \mathrm{g} \times \mathrm{K}$ at the $150^{\circ} \mathrm{C}$ ). 


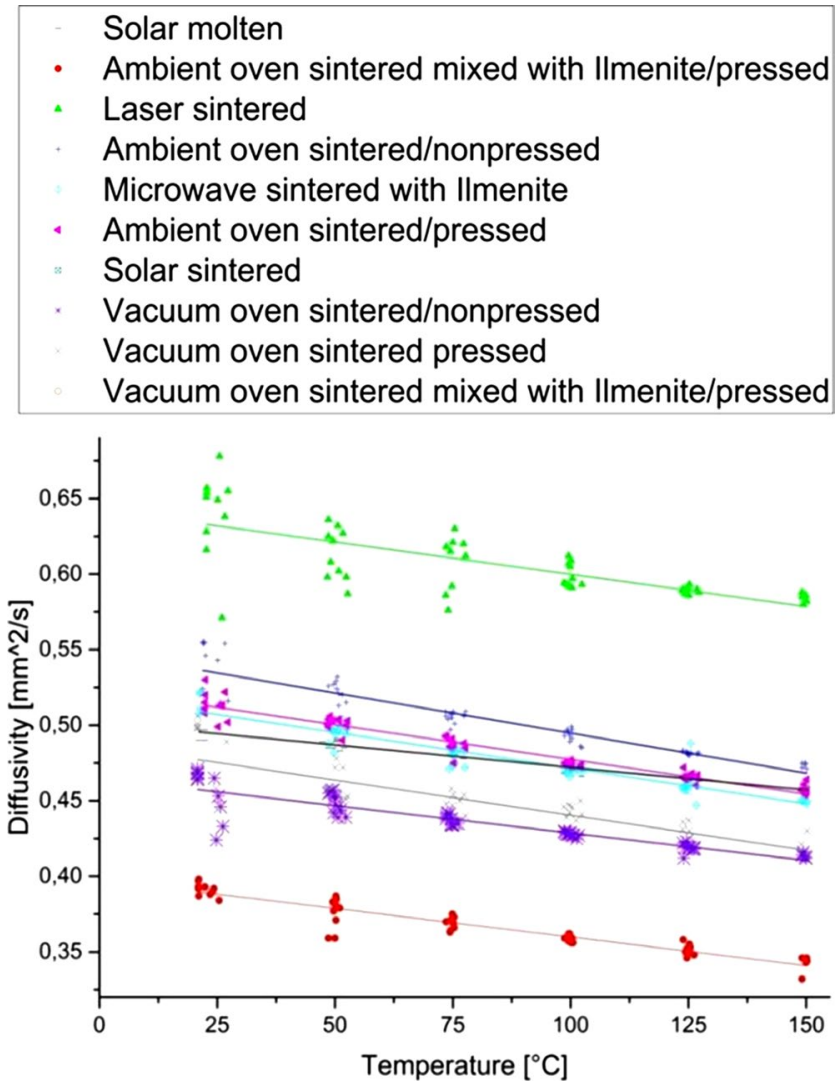

F I G U RE 6 Thermal diffusivity measurement results of different processed samples

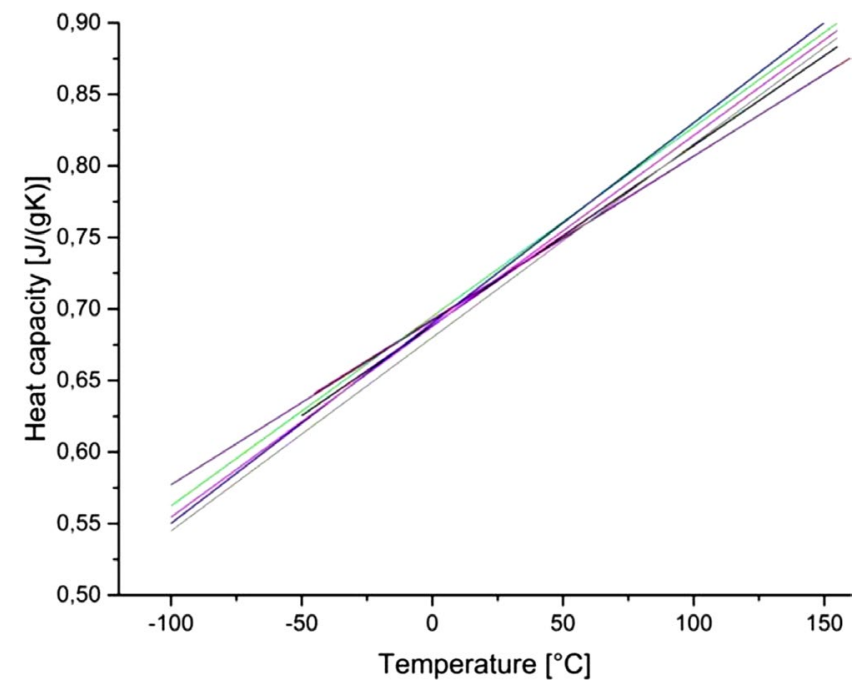

F I G U RE 7 Heat capacity measurement results of different processed samples (legends are presented in Figure 6)

The second highest thermal conductivity value after the SLM part, belonged to traditionally oven sintered samples.

Results showed that, pressed and non-pressed samples showed similar thermal conductivity values independent of

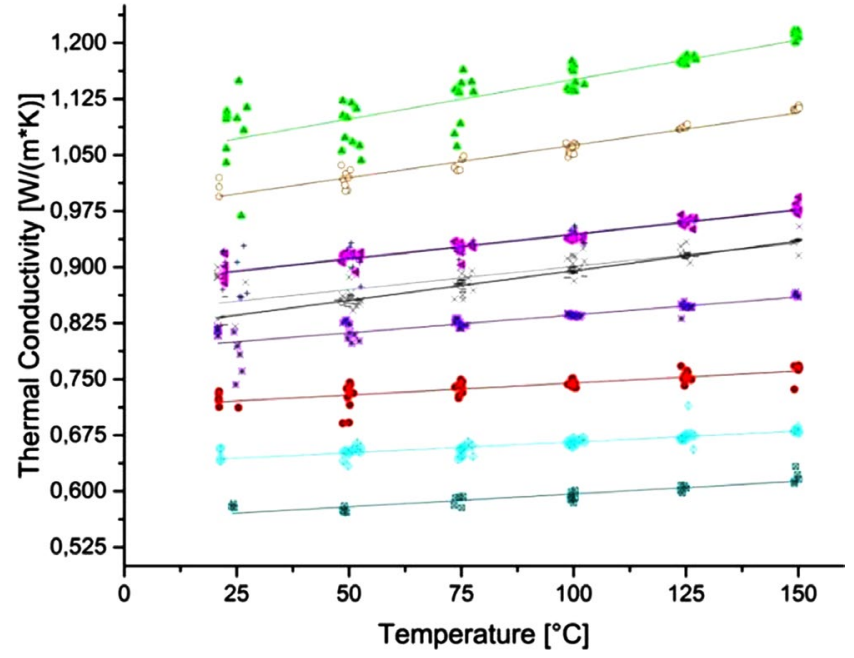

F I G U RE 8 Thermal conductivity measurement results of different processed samples (legends are presented in Figure 6)

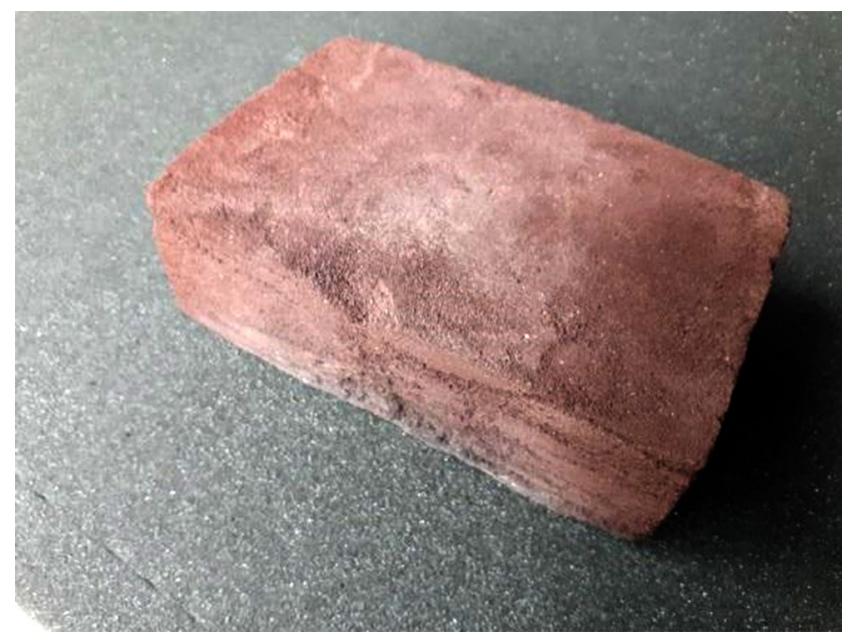

F I G U R E 9 Demonstrator brick of JSC-2A sintered under ambient conditions. JSC, Johnson Space Center

the fabrication atmosphere. The vacuum sintered parts using JSC-2A exhibited lower thermal conductivity (approximately $12 \%$ ) compared to the samples sintered under ambient condition.

Thermal conductivity of the samples did not necessarily improve (in all sintering methods) by mixing the regolith with the ilmenite powder.

Moreover, to better compare our results, the thermal conductivity of terrestrial materials for construction applications such as quartz, granite and basalt was reviewed. It is reported 22 that the construction materials exhibit an average thermal conductivity of $2.7 \mathrm{~W} / \mathrm{m} \times \mathrm{K}$ which is approximately two to three times more conductive compared to the sintered samples mentioned in Figure 8. Moreover, quartz material exhibited the highest thermal conductivity $(5.17 \mathrm{~W} / \mathrm{m} \times \mathrm{K})$ among 
the reviewed materials and studied samples in this investigation. ${ }^{22}$

\section{6 | Application}

Thermal storage system on the Moon could benefit from sintered regolith blocks (targeted as the thermal energy storage object) in order to release the heat after a defined period of time.

This can be followed using the released heat energy as an input energy to run a heat engine for electricity generation. Toward this application, a brick with a size of $143 \times 87 \times 50 \mathrm{~mm}^{3}$ was fabricated by sintering the loose regolith under air. Bulk simulant was poured into a machined-fire brick mould and sintered using the mentioned parameters in methodology section. It should be noted that, vacuum sintered parts, represent a more similar condition for manufacturing on the Moon. However, due to the lack of available sintering oven fulfilling the demonstrator size factor, brick was sintered under ambient conditions. Integration of the sintered brick in an experimental setup ${ }^{23}$ could be beneficial in order to validate the simulation models for the thermal storage application. Furthermore, the measured thermal conductivity values of all the sintered samples (see Figure 3), could be helpful for many future ISRU investigations. ${ }^{23}$

Fabricated brick out of JSC-2A (sintered under ambient conditions) is shown in Figure 9.

\section{5 | CONCLUSIONS}

Various samples using different fabrication techniques such as laser, solar, microwave and traditional oven sintering under different working atmospheres were fabricated and analyzed regarding their density, thermal diffusivity, heat capacity and consequently, thermal conductivity. Solar sintered samples resulted in a density of approximately $54 \%$ of regolith's true density. Ambient oven sintered of JSC-2A mixed with ilmenite/pressed and vacuum sintered JSC-2A/pressed yielded the highest densities among the studied samples representative of $89 \%$ and $86 \%$ of regolith's true density, respectively. Non-pressed sintered regolith under vacuum showed a similar density to the pressed sintered regolith under ambient conditions.

Among the LFA measured samples, laser sintered part, represented the highest thermal diffusivity value. In general, results regarding the thermal diffusivity measurements showed a contradictory trend compared to the density measurement results. Following this trend, ambient oven sintered mixed with ilmenite/pressed exhibited the lowest thermal diffusivity among the studied samples. Heat capacity measurements showed that, the measured heat capacity values were not varying significantly at constant temperatures, regardless of the applied manufacturing techniques.

Thermal conductivity measurements showed that thermal conductivity increases for each individual sample (regardless of the sintering technique) approximately $10 \%$ within the temperature range of $25^{\circ} \mathrm{C}$ to $150^{\circ} \mathrm{C}$. Laser sintered JSC-2A exhibited the highest thermal conductivity of approximately $1.1 \mathrm{~W} / \mathrm{m} \times \mathrm{K}$ at room temperature compared to other sintered samples. Vacuum sintered samples showed a lower thermal conductivity compared to the ones sintered under the air (approximately $12 \%$ ). The terrestrial construction materials (reviewed in this study) exhibited an average thermal conductivity of $2.7 \mathrm{~W} / \mathrm{m} \times \mathrm{K}$ which is approximately two to three times more conductive compared to the studied sintered samples for lunar application. In this study, a brick (size of $143 \times 87 \times 50$ $\mathrm{mm}^{3}$ ) was successfully fabricated by sintering the loose regolith under ambient condition. This demonstrated the feasibility of sintering of regolith simulant for relatively big objects for various applications. Presented work would be also beneficial in order to validate simulation models for many lunar explorations such as the Moon energy storage and generation.

\section{ACKNOWLEDGMENTS}

We acknowledge funding from the ESA GSP study "MESG: Moon Energy Storage and Generation: open call $\mathrm{A}=/ 1-8712 / 16 / \mathrm{F} / \mathrm{MOS}$ issued by the European Space Agency via EMITS in September 2016. The authors thank all the MESG partners: Sonaca Space GmbH, BlueThink S.p.A., and OHB System AG. The authors also thank Dr. Christian Neumann and Dr. Alexandre Meurisse from Institute of Materials Physics in Space (DLR) for their feedback during the project.

\section{ORCID}

Miranda Fateri (D) https://orcid.org/0000-0001-8879-9272

\section{REFERENCES}

1. ISEC Global Exploration Roadmap. 3rd ed. Washington: ISEC; 2018.

2. Heiken G, Vaniman D, French BM. Lunar source book: a users guide to the moon. Cambridge: Cambridge University Press; 1991.

3. Carpenter J, Fisackerly R, Houdou B. Establishing lunar resource viability. Space Policy. 2016;37:52-7.

4. Fateri M, Pitikaris S, Sperl M. Investigation on wetting and melting behavior of lunar regolith simulant for additive manufacturing application. Microgravity Sci Technol. 2019;31:161-7.

5. Taylor LA, Pieters C, Britt D. Evaluations of lunar regolith simulants. Planet Space Sci. 2016;126:1-7.

6. Laul JC, Papike JJ, Simon SB. The lunar regolith-comparative studies of the Apollo and Luna sites, chemistry of soils from Apollo 17, Luna 16, 20, and 24. Proc Lunar Planet Sci. 1981;12B:389. 
7. Rickman D, McLemore C, Fikes J. Characterization summary of JSC-1A bulk lunar mare regolith simulant. National Aeronautics and Space Administration. 2007.

8. Taylor LA, Liu Y. Important consideration for lunar regolith simulants. In ASCE. Earth and space 2010: engineering, science, construction, and operations in challenging environments. 2010; p. 106-18.

9. Cesaretti G, Dini E, Kestelier XD, Colla V, Pambaguian L. Building components for an outpost on the lunar soil by means of a novel 3D printing technology. Acta Astronaut. 2014;93:430-50.

10. Jakus AE, Koube KD, Geisendorfer NR, Shah RN. Robust and elastic lunar and martian structures from 3d-printed regolith inks. Sci Rep. 2017;7:44931.

11. Chow BJ, Chen T, Zhong Y, Qiao Y. Direct formation of structural components using a martian soil simulant. Sci Rep. 2017;7:1151.

12. Balla VK, Roberson LB, O'Connor GW, Trigwell S, Bose S, Bandyopadhyay A. First demonstration on direct laser fabrication of lunar regolith parts. Rapid Prototyp J. 2012;18:451-7.

13. Taylor LA, Meek TT. Microwave sintering of lunar soil: properties, theory, and practice. J Aerosp Eng. 2005;18:188-96.

14. Nakamura T, Smith B. Solar thermal system for lunar ISRU applications: development and field operation at Mauna Kea. In: Proceedings of the 49th, Aerospace sciences meeting; 49th AIAA Aerospace Sciences meeting including the New Horizons Forum and Aerospace Exposition 2011; 2011; Orlando, FL. Vol. 7. Reston, VA: American Institute of Aeronautics and Astronautics, 2011; p. 5759-5774.

15. Fateri M, Gebhardt A. Process parameters development of selective laser melting of lunar regolith for on-site manufacturing applications. Int J Appl Ceram Technol. 2015;12:46-52.

16. Fateri M, Gebhardt A, Khosravi M. Experimental investigation of selective laser melting of lunar regolith for in-situ applications. In: Proceedings of the ASME 2013 International Mechanical Engineering Congress and Exposition. Vol. 2A: Advanced Manufacturing. San Diego, CA: American Society of Mechanical Engineers. 2014; p. V02AT02A008.

17. Street KW, Ray C, Rickman D, Scheiman DA. Thermal properties of lunar regolith simulants. In: Proceedings of Earth and Space
2010: Engineering, Science, Construction, and Operations in Challenging Environments, Honolulu, HI. Reston, VA: American Society of Civil Engineers, 2010; p. 266-275.

18. Meurisse A, Beltzung JC, Kolbe M, Cowley A, Sperl M. Influence of mineral composition on sintering lunar regolith. J Aerosp Eng. 2017;30:04017014.

19. Urbina D, Madakashira H, Salini J, Govindaraj S, Bjoerstad R, Gancet J, et al. Robotic prototypes for the solar sintering of regolith on the lunar surface developed within the Regolight project. In: 68th International Astronautical Congress (IAC), Adelaide, Australia, 25-29 September 2017. Paris, France: International Astronautical Federation; 2017.

20. Cowley A, Salter J, Gutsche K, Barad L, Pedrazanni M, Fateri M, Meurisse A. In-situ resource-driven approaches to additive manufacturing using lunar regolith simulant. Paper presented at the Annual Meeting of the Lunar Exploration Analysis Group; November 1 2017; Columbia, MD.

21. Cape JA, Lehman GW. Temperature and finite pulse-time effects in the flash method for measuring thermal diffusivity. J Appl Phys. 1963;34:1909-13.

22. Kim KH, Jeon SE, Kim JK, Yang S. An experimental study on thermal conductivity of concrete. Cem Concr Res. 2003;33: 363-71.

23. Celotti L, Piskacev M, Nadalini R, Mazzetti A, Pret MG, Guardabasso P, et al. Design and assessment of a system for moon energy storage and generation. In: 69th International Astronautical Congress (IAC) Bremen, Germany, 1-5 October 2018. International Astronautical Federation; 2018.

How to cite this article: Fateri M, Sottong R, Kolbe M, Gamer J, Sperl M, Cowley A. Thermal properties of processed lunar regolith simulant. Int J Appl Ceram Technol. 2019;00:1-10. https://doi.org/10.1111/ ijac. 13267 